\title{
A novel text message--based motivational interviewing intervention for college students who smoke cigarettes
}

\author{
Anno Jorayeva' , S. Lee Ridner', Lynne Holl' ${ }^{1}$, Ruth Stoten ${ }^{1}$, Kondi L. Wolker
}

\begin{abstract}
INTRODUction Tobacco use disorder is critical among people aged 16 to 25 years. College campuses are prime locations for smoking cessation interventions for young adults. The vast majority of the smoking research with college students has been epidemiological in nature. This study examined a novel motivational interviewing intervention designed for college students, and explored predictors of smoking behavior change.

METHODS A quasi-experimental one group pretest-posttest design with repeated measures was used to evaluate a novel text message-based brief motivational interviewing intervention. The data were collected from undergraduate students ( $\mathrm{N}=33$ ) who smoked cigarettes in Fall 2015. RESULTS Students' level of autonomy and relatedness needs satisfaction, autonomous motivation, and smoking cessation self-efficacy increased $(\mathrm{p}<0.05)$, and their rate of daily smoking declined ( $\mathrm{p}<0$.05) over time. However, competence need satisfaction, readiness to quit smoking and severity of nicotine addiction remained unchanged. Smoking cessation self-efficacy was the strongest predictor of smoking behavior change in college students.

conclusions This study adds to the knowledge on smoking behavior among college students. Preliminary evidence indicates that text message-based motivational interviewing and smoking cessation self-efficacy may help guide successful smoking behavior interventions for college

students.
\end{abstract}

\section{AFFILIATION \\ 1 University of Louisville, \\ Louisville, Kentucky, USA \\ CORRESPONDENCE TO \\ Anna Jorayeva. University of \\ Louisville, 555 S Floyd St, \\ 40202 Louisville, Kentucky, USA \\ E-mail: a0joraO1@cardmail. \\ louisville.edu}

\section{KEYWORDS}

smoking cessation, cigarette

smoking, college, smoking

behavior, motivational

interviewing, text message

Received: 28 May 2017

Revised: 8 October 2017

Accepted: 11 October 2017

\section{INTRODUCTION}

In 2013, there were approximately 1.1 billion tobacco smokers in the world ${ }^{1}$. Every year, smoking claims about six million lives and causes approximately half a trillion dollars in economic damage ${ }^{2}$. Cigarette smoking is a critical health concern in the $\mathrm{USA}^{3}$. Although the decrease in the number of people who smoke over the last decade is encouraging, 36.5 million Americans continue to smoke ${ }^{3}$. Smoking causes more than $20 \%$ of all annual deaths in the $\mathrm{USA}^{4}$ and accounts for approximately $\$ 170$ billion dollars, or $1 \%$ of the gross domestic product, in health-care cost ${ }^{5}$.

Cigarette smoking is a significant concern in the young adult population ${ }^{3}$. With the freedom to make self-initiated choices, some choose to engage in health-risk behaviors that have far-reaching effects. About $13 \%$ of young adults (1824 years old) smoke cigarettes ${ }^{3}$. Of the 15 million young adults who attend colleges and universities in the $\mathrm{USA}^{6}$ approximately $10 \%$ smoke cigarettes ${ }^{7}$. Cigarette smoking among college students presents a significant danger for health and well being and poses serious consequences, such as the loss of a decade of life $\mathrm{e}^{8,9}$.

The majority of the chronic health conditions that plague the USA adult population is preventable or remediable through behavioral change ${ }^{10}$. Quitting smoking is the single most important health behavior change most smokers can make. The vast majority of the smoking research with college students has been epidemiological in nature. To date, there have been few behavioral interventions targeting smoking cessation among college students. Tobacco use disorder is critical during young adulthood, a time of new emerging social influences and individual psychosocial vulnerabilities ${ }^{11}$. College campuses are prime locations for smoking cessation interventions for 
young adults, as college years are often the time when many adults either establish lifelong cigarette smoking or abandon $\mathrm{it}^{12}$. Because adolescents and young adults are unlikely to seek traditional cessation therapies ${ }^{13}$, innovative smoking cessation interventions are essential to reach and engage this population. Integrating mobile technology may increase college students' participation in smoking cessation ${ }^{14}$.

Currently, various evidence-based approaches are used in smoking cessation. The most popular ones in the college setting include: environmental strategies, cognitive-behavioral therapy, nicotine replacement therapy, self-help, and group or individual counseling interventions ${ }^{15}$. One approach that has not been well evaluated in this group is the use of motivational interviewing. To our knowledge, there are no studies on the adaptation of text messages to real-time, interactive motivational interviewing as a smoking behavior intervention. Motivational interviewing (MI) provided the content for the intervention messages. MI is a person-centered method of counseling that elicits and strengthens the individual's motivation for a behavioral change $\mathrm{e}^{16}$. It is often described as a communication approach in which difficulties of behavioral change and possibilities of engagement in healthier behavior are discussed in a respectful manner, and in accord with the client's own goals, reasons, and values ${ }^{16}$.

Several studies have demonstrated efficacy and acceptability of text messaging in the field of smoking cessation across different populations ${ }^{17-24}$. In a recent systematic review and meta-analysis of 22 smoking cessation interventions, text messaging was found to be effective in reducing cigarette consumption relative to controls $(\mathrm{d}+=0.14,95 \% \mathrm{CI}=0.05$, $0.23, \mathrm{k}=9)$, and increasing 7 day point prevalence $(\mathrm{OR}=1.38$, $95 \% \mathrm{CI}=1.19,1.55, \mathrm{k}=16)$ and continuous smoking abstinence $(\mathrm{OR}=1.63,95 \% \mathrm{CI}=1.19,2.24, \mathrm{k}=7)^{21}$.

Research on the use of MI in tobacco control is also quite extensive. In the 2013 smoking cessation review of the clinical cessation evidence, MI strategies were found effective in increasing the quit attempts ${ }^{25}$. A comprehensive systematic analysis of MI in smoking cessation found a statistically significant effect of $\mathrm{MI}$ on abstinence $(\mathrm{OR}=1.45$, 95\% CI $=1.14-1.83$ ) and a sustained superiority of MI over control condition across time. The odds ratio for the MI effect for adolescents was 2.29 (95\% CI=1.34-3.89) and 1.44 (95\% CI $=1.04-2.01$ ) for adults. ${ }^{26}$ There is only one known study that adapted text messaging to motivational interviewing in an automated texting protocol and the intervention was successful in producing a positive change in smoking behavior ${ }^{27}$.

The objectives of this study were to: 1 ) examine changes in smoking behavior among college students who participated in the novel, theory and evidence-based motivational interviewing intervention (MI), and 2) identify predictors of change in cigarette smoking behavior.

Self-Determination Theory (SDT) provided the theoretical foundation for this pilot study. SDT is a broad-based motivational theory that focuses specifically on regulation of human motivation to engage in a healthy behavior ${ }^{28}$. SDT suggests that individuals' motivation to change is facilitated by the satisfaction of the basic psychological needs of autonomy, competence, and relatedness ${ }^{29,30}$. According to SDT, engagement and maintenance of health behaviors, such as quitting smoking, rely heavily on the behavior regulation process - an active course of internalization of an externally prompted behavior within an experience of autonomy, relatedness and sense of competence. From this perspective, it is essential for the clinicians to help young adults, who are in a transitional stage of development (age of identity exploration), feel that they: 1) have autonomously chosen their behavior change, 2) can succeed at it, and 3) connect with and trust the clinician they are working with (and other significant people) while undergoing the change ${ }^{28}$. All three goals are brought together through the application of motivational interviewing processes of engaging the client into a therapeutic alliance, focusing on the 'what' and 'why' of cigarette smoking, evoking arguments for change, and planning actions for smoking behavior change ${ }^{31}$.

\section{The specific aims of this study were to:}

1. Evaluate changes in cognitive parameters of behavior regulation processes (psychological needs satisfaction, autonomous motivation, smoking cessation self-efficacy, and readiness to quit) among college students who participated in the MI intervention.

2. Evaluate changes in smoking behavior (number of cigarettes smoked per day and severity of nicotine addiction) between baseline and 2-week post-intervention follow-up.

3. Identify independent predictors of change in number of cigarettes smoked per day among college students, from baseline to 2-week post-intervention follow-up.

\section{METHODS}

\section{Design}

A quasi-experimental one-group pretest-posttest design with repeated measures was used to evaluate the changes in cognitive parameters of behavior regulation processes among college students who participated in a text message-based brief motivational interviewing intervention. Data were collected at three time points using a web-based self-report survey that 
included a series of standardized instruments. Participants completed a survey at baseline, following the intervention (which lasted approximately three weeks), and at a 2 -week post-intervention follow-up. Behavioral parameters (severity of nicotine addiction, number of cigarettes per day) were the major outcomes. Cognitive parameters of behavior regulation processes (psychological needs satisfaction, autonomous motivation, smoking cessation self-efficacy, and readiness to quit) were the intermediary outcomes.

\section{Somple}

The power analysis was conducted using average effect sizes reported in meta-analytic reviews of both motivationalinterviewing $(\mathrm{d}=0.21-0.35)^{32}$ and text-messaging $(\mathrm{RR}=$ 1.50 [95\% CI $0.92-2.44$ ] -2.20 [95\% CI $1.79-2.70])^{33}$ interventions on smoking cessation to estimate the appropriate sample size. With three repeated measurements, an estimated correlation among the repeated measures of 0.50 , and an a level of 0.05 , a sample size of 30 of participants was needed ( 27 being the recommended number, plus 10\% [3 participants] for projected attrition) to detect an effect size of 0.25 , with a power of $0.80^{34,35}$. Students were oversampled by three to ensure adequate power, bringing the total number of participants to 33 .

A non-probability convenience sample of 33 students was recruited from a metropolitan university in the Mid-South region of the USA. The inclusion criteria were: age 18-24 years, current smoking status, active university enrolment, ability to read and understand English, ability to send and receive text messages, and access to the Internet. Exclusion criteria were: severe illness, physical disability, current psychiatric/mental health diagnosis or treatment, unwillingness to use the text message technology, and current or planned pregnancy within the study timeframe.

\section{Measures}

\section{Basic-needs satisfaction}

Theory-specific Basic Needs Satisfaction in General Scale $\left(\right.$ BNSG-S) ${ }^{30,36}$ was used to assess three basic psychological needs as postulated by the Self-Determination Theory: autonomy, competence, and relatedness need to be fulfilled for psychological and physical well-being to occur in a general context. The BNSG-S is a self-report questionnaire consisting of 21 items (3 subscales), examining the extent of psychological needs satisfaction; response options range from 1 (not true at all) to 7 (definitely true). The average of the item scores on each subscale represents the degree to which a person experiences satisfaction of that respective need. Higher scores represent greater psychological need satisfaction. Research in general population samples, including college student samples, has demonstrated variable support for the BNSG-S internal consistency reliability $(a=0.55-0.89)^{37,38}$.

\section{Autonomous motivation}

Autonomous motivation to stop smoking was evaluated using the 15-item SDT-based Treatment Self-Regulation Questionnaire (TSRQ) ${ }^{39}$, which assessed motivation to engage in smoking cessation. Each item represents a potential reason to quit smoking and is rated on a 7-point scale ranging from 'not at all true' to 'very true'. Participants respond to: 'The reason I would not smoke is...'. The responses are scored and averaged per subscale (autonomous motivation, introjection, external regulation, and amotivation $)^{40}$. Higher scores indicate a greater level of motivation. Data obtained with TSRQ have demonstrated good internal consistency reliability in samples of the general adult population across different behavioral domains $(a=0.73-0.93)^{40-42}$.

\section{Smoking cessation self-efficacy}

The 12-item Smoking Self-Efficacy Questionnaire (SEQ-12) ${ }^{43}$ was used to assess students' smoking cessation self-efficacy, i.e. the confidence in the ability to abstain from smoking in the high-risk situations. The response options range from 1 (not at all sure) to 5 (absolutely sure). The SEQ-12 scores range from 12 to 60 ; higher scores indicate greater self-efficacy. The reliability of the SEQ-12 data was supported in a sample of the general population $(a=0.93-0.95)^{43}$.

\section{Readiness to quit}

Readiness to quit smoking was measured by the Contemplation Ladder $^{44}$, which is a quasi-continuous measure of readiness to change a specific behavior. The ladder contains 11 rungs starting with $0=$ 'No thought of quitting', and culminating with $10=$ 'Taking action to quit'. Higher scores represent greater motivation to change $\mathrm{e}^{44}$. Prior research with samples from the general adult population supported Ladder's discriminant ${ }^{44,45}$ and predictive validity ${ }^{46-48}$.

\section{Severity of nicotine addiction}

Severity of nicotine addiction was measured by the Cigarette Dependence Scale (CDS-12) ${ }^{49}$, which was developed based on signs indicative of addiction to cigarettes, systematic psychometric considerations, and addiction content coverage.

The scale is a continuous self-report measure composed of 12 items that assess the primary symptoms of nicotine dependence, reflected by the DSM-IV and ICD-10 criteria, except for tolerance. The items are both continuous and 
multiple choice (scores range from 1 to 5 ) and are scored using an algorithm; total scores range from 12 (low dependence) to 60 (high dependence). Internal consistency of the instrument was supported in samples of the general population $(a=0.84$ $-0.97)^{50-52}$.

\section{Demographic characteristics}

A demographic questionnaire was used to collect data on: age, sex, year in school, past smoking history (including the number of close friends/family members who smoke), grade point average (GPA), socioeconomic status (SES), sorority/ fraternity membership, alcohol use, and sexual orientation.

\section{Intervention}

Intervention was carried out by a master's prepared registered nurse, who was formally trained and experienced in smoking cessation motivational interviewing. Intervention text messages were built on the fundamental processes of motivational interviewing by: engaging the smoker in a respectful relationship, focusing on the goals, evoking change talk, and developing a change plan. The messages were manually transmitted in real-time between participant and the interventionist ${ }^{31}$. Participants received up to three text message contacts lasting about 30 minutes in total engagement time on a weekly basis for an intervention period lasting about three weeks. This intensity was informed by the findings of the systematic review of smoking cessation interventions for young adults ${ }^{53}$, where the average number of contacts in the college sample was about four (range: 1-20), and the findings of the metaanalysis of diverse populations indicating that intervention effect was maximized when multiple text messages per day were used $(g=0.395)^{54}$. A brief treatment manual was used to ensure consistent protocol within treatment contacts.
During the text message motivational interview, the interventionist used reflective listening to emphasize change discussions, remained non confrontational, yet directed the conversation towards developing participant's personal reasons for change, reinforcing the decision to change, and elaborating an individualized plan for smoking behavior change for those who decided to reduce or stop smoking. Although leading questions and statements were planned in advance according to theoretical and clinical evidence guidelines, the interviewer used various MI techniques to guide the discussions based on participant data and some of the messages were created that moment rather than prior to the intervention. Table 1 presents the psychological needs as proposed by Self-Determination Theory, the fundamental processes of MI, and select MI intervention text messages that were written both prior and actively during the intervention.

\section{Procedure}

The University's Institutional Review Board approved the study protocol. Informed consent was obtained using a preamble letter presented to each student who chose to participate and completed the baseline survey.

Participants were actively recruited through school orientation activities, school-wide emails, and by posting informational flyers at key student sites during the Fall 2015 semester. Referrals and information on free alternative services $^{55}$ (such as Kentucky's Tobacco Quit Line, Cooper Clayton classes, SmokefreeTXT program, etc.) were offered to all students with active smoking status, those who met the exclusion criteria or chose not to participate received the information upon initial contact and to study the participants at the end of the research. A total of 64 students who identified as a cigarette smoker were screened, four students

\section{Table 1. A sample of customizable motivational interviewing (MI) intervention messages used in the study based on Self Determination Theory.}

\begin{tabular}{|c|c|c|}
\hline $\begin{array}{l}\text { Psychological } \\
\text { Need }\end{array}$ & $\begin{array}{l}\text { Fundamental VII } \\
\text { Process }\end{array}$ & VI messages \\
\hline Autonomy & Engaging & $\begin{array}{l}\text { What is your smoking story? } \\
\text { It's totally up to you to decide if and when you are ready to make any lifestyle changes. } \\
\text { Whatever you choose, I'm here to listen and support you. }\end{array}$ \\
\hline \multirow[t]{2}{*}{ Relatedness } & Focusing & $\begin{array}{l}\text { I want to learn about your smoking to understand how it impacts your life and what, if anything, you want to do about it. } \\
\text { What change in your smoking behavior do you think might make the biggest difference, if at all, for you? }\end{array}$ \\
\hline & Evoking & $\begin{array}{l}\text { What things in life are important to you? How does smoking fit into that? } \\
\text { What difficulties in your life do you think your smoking helped to create? What would be the benefits of quitting and its } \\
\text { drawbacks? }\end{array}$ \\
\hline Competence & Planning & $\begin{array}{l}\text { Have you ever attempted/thought of attempting to quit? What was/would be helpful? What kinds of difficulties did/would } \\
\text { you expect? How do you think you could deal with them? } \\
\text { Which family members/friends could support you as you make the change? } \\
\text { What steps, if any, have you already taken? What would be your next step? }\end{array}$ \\
\hline
\end{tabular}

Note. Categorization of presented relationships is not binary or linear. 
did not meet the enrolment criteria, and 27 declined the invitation to take part in the research. The students who chose to participate received a $\$ 10$ incentive through Chase Person-to-Person Quick Pay ${ }^{\mathrm{TM} 56}$ for their time at the end of each survey.

The questionnaires were completed using a secure data collection and management application -Research Electronic Data Capture (REDCap) ${ }^{57}$. Pertinent information (such as smoking habit, triggers, history) was abstracted and used to design individualized text message motivational interviewing sessions. All participants provided windows of time during weekdays and weekends that they were available for text message conversation. Most of communication attempts were conducted in the evening and over the weekends.

\section{Data analysis}

Data analysis was conducted with the $\mathrm{IBM}^{\circledR} \mathrm{SPSS}^{\circledR}$ Statistics software, Version $21^{58}$. Alpha was set at $<0.05$ for all statistical tests. Data were checked for the outliers (+/- 3SD) and corrected (e.g. Huynh-Feldt) when all test assumptions were not met. Repeated measures analyses of variance (ANOVA) were used to evaluate changes in cognitive parameters of behavior regulation (psychological needs satisfaction, autonomous motivation, smoking self-efficacy, and readiness to quit) and smoking behavior (number of cigarettes smoked per day and severity of nicotine addiction) of the students measured at baseline (T1), immediately after completion of the intervention (T2), and at a 2-week post-intervention follow-up (T3). Hierarchical multiple regression analysis was used to identify behavior regulation predictors of change in smoking behavior (number of cigarettes smoked per day) of the college students. To address possible regression toward the mean, baseline scores of the number of cigarettes smoked per day were forced into the model as a confounding variable (block 1 ). To lower the risk of a Type II error, the backward elimination method was used (block 2). Change scores were computed to identify the changes in the behavior regulation and behavior parameters from baseline - T1 to the end of the study - T3 (follow up). Inspection of the correlations among the study variables revealed that smoking cessation self-efficacy $(r=$ $-0.66, \mathrm{p}<0.01)$, relatedness need satisfaction $(\mathrm{r}=-0.44$, $\mathrm{p}<0.05)$, and the number of close friends who smoke $(\mathrm{r}$ $=0.35, \mathrm{p}<0.05$ ) were correlated with the change in the number of cigarettes students smoked per day. None of the demographic variables was associated with both dependent (outcome) and independent (predictors) variables; thus, no demographic characteristics were included as covariates in the analyses.

\section{RESULTS}

\section{Demographic characteristics of the sample}

Overall, the mean age of the participants was $20(\mathrm{SD}=2.1)$ years, $46 \%$ were female, and 76\% were Caucasian. At baseline, the mean number of cigarettes smoked per day was 9 (range: $2-20, \mathrm{SD}=7)$. Number of friends $(\mathrm{r}=0.45, \mathrm{p}<0.01)$ and family members $(r=0.36, p<0.05)$ who smoke, alcohol consumption [drinks per week $(\mathrm{r}=0.45, \mathrm{p}<0.01)$, drinks per occasion $(\mathrm{r}=0.42, \mathrm{p}<0.05)]$, and years of smoking $(\mathrm{r}=$ $0.50, \mathrm{p}<0.01)$, were positively correlated with the number of cigarettes smoked per day.

Changes in cognitive parameters of behavioral regulation and smoking behavior

Statistical values of change in cognitive parameters of behavior regulation and smoking behavior are shown in Table 2 . Bonferroni correction was used to reduce the chances of Type I error. There was a significant change in autonomy need satisfaction $(p<0.05)$. Follow-up comparisons indicated that there were increases in scores between baseline and the two time points post-intervention ( $\mathrm{p}<0.05$ ); however, there was no significant difference in mean autonomy need satisfaction between the two post intervention follow-ups ( $p>0.05)$.

For competence need satisfaction, the statistical assumption of sphericity was violated and the degrees of freedom were corrected using Huynh-Feldt estimates. There were no significant changes in competence need satisfaction from baseline to post-intervention follow-ups ( $p>0.05)$.

A similar statistical assumption violation occurred with relatedness need satisfaction scores. The degrees of freedom were corrected using Huynh-Feldt estimates of sphericity and the adjusted results yielded a significant effect of time. Thus, students' relatedness need satisfaction increased over time $(\mathrm{p}<0.05)$. The pairwise comparisons revealed a significant difference only between T1 and T3 scores $(\mathrm{p}<0.05)$; baseline scores were significantly lower than the two-week follow-up scores.

There was a significant effect of time on autonomous motivation ( $\mathrm{p}<0.05$ ). Follow-up comparisons revealed significant increases in the scores between baseline and the two time points post intervention ( $p<0.05)$; however, there was no significant difference between T2 and T3 scores ( $p>$ $0.05)$.

There was a significant time effect on smoking cessation selfefficacy. Pairwise comparisons revealed significant increases in the scores between baseline and the two time points postintervention $(\mathrm{p}<0.05)$. Mean smoking cessation self-efficacy scores at T2 and T3 did not differ ( $p>0$.05). 
Research paper

Table 2. Changes in behavior regulation and smoking behavior across time $(\mathrm{N}=33)$.

\begin{tabular}{|c|c|c|c|c|c|c|c|c|c|c|c|}
\hline \multirow[b]{2}{*}{ Variable } & \multicolumn{2}{|c|}{ Timel } & \multicolumn{2}{|c|}{ Time 2} & \multicolumn{2}{|c|}{ Tine3 } & \multirow[b]{2}{*}{$\Lambda$} & \multirow[b]{2}{*}{ Df } & \multirow[b]{2}{*}{$\mathbf{F}$} & \multirow[b]{2}{*}{$n^{2}$} & \multirow{2}{*}{$\begin{array}{l}\text { Group } \\
\text { Difference } \\
\text { (Bonferroni) }\end{array}$} \\
\hline & $M$ & $S D$ & $M$ & SD & $M$ & SD & & & & & \\
\hline Autonomy need & 4.69 & 0.67 & 5.52 & 0.55 & 5.55 & 0.48 & 0.40 & 2,31 & $23.46^{*}$ & 0.60 & $1<2,3$ \\
\hline $\begin{array}{l}\text { Competence } \\
\text { need }\end{array}$ & 5.41 & 0.67 & 5.69 & 0.84 & 5.48 & 0.74 & & $1.7,54.7$ & 1.81 & 0.05 & $1<2,3$ \\
\hline $\begin{array}{l}\text { Relatedness } \\
\text { need }\end{array}$ & 5.20 & 1.00 & 5.54 & 0.70 & 5.68 & 0.52 & & $1.7,55.1$ & $7.31^{*}$ & 0.19 & $1<3$ \\
\hline $\begin{array}{l}\text { Autonomous } \\
\text { motivation }\end{array}$ & 2.11 & 0.77 & 3.87 & 0.52 & 3.69 & 1.04 & 0.19 & 2,31 & $66.59^{*}$ & 0.81 & $1<2,3$ \\
\hline $\begin{array}{l}\text { Smoking self- } \\
\text { efficacy }\end{array}$ & 40.60 & 7.60 & 45.42 & 7.27 & 46.58 & 8.20 & 0.55 & 2,31 & $12.56^{*}$ & 0.45 & $1<2,3$ \\
\hline $\begin{array}{l}\text { Readiness } \\
\text { to quit }\end{array}$ & 4.45 & 2.97 & 5.15 & 2.98 & 4.67 & 3.14 & 0.93 & 2,31 & 1.13 & 0.07 & $1<2,3$ \\
\hline $\begin{array}{l}\text { Cigarettes } \\
\text { smoked per day }\end{array}$ & 9.09 & 6.98 & 3.76 & 2.86 & 4.82 & 4.48 & & $1.63,52$ & $16.88^{*}$ & 0.35 & $1>2,3$ \\
\hline $\begin{array}{l}\text { Severity } \\
\text { of nicotine } \\
\text { addiction }\end{array}$ & 23.24 & 7.00 & 22.06 & 5.88 & 21.94 & 6.25 & 0.84 & 2,31 & 3.02 & 0.16 & $\begin{array}{l}1>2,3 \\
2>3\end{array}$ \\
\hline
\end{tabular}

Note. Categorization of presented relationships is not binary or linear.

Table 3. Hierarchical multiple regression analysis predicting number of cigarettes smoked per day by college students $(\mathrm{N}=33)$.

\begin{tabular}{|c|c|c|c|c|}
\hline \multicolumn{5}{|c|}{ Cigarettes smoked per day } \\
\hline Variable & $\Delta R^{2}$ & B & $B$ & SE B \\
\hline Step 1 & $0.60^{* *}$ & & & \\
\hline \multicolumn{5}{|l|}{ Control variable ${ }^{a}$} \\
\hline Step 2 & $0.17^{* *}$ & & & \\
\hline Close-friends smoking & & 0.02 & 0.04 & 0.31 \\
\hline $\begin{array}{l}\text { Relatedness need } \\
\text { satisfaction }\end{array}$ & & -0.09 & -0.61 & 0.74 \\
\hline $\begin{array}{l}\text { Smoking cessation } \\
\text { self-efficacy }\end{array}$ & & $-0.40^{* *}$ & -0.35 & 0.09 \\
\hline Total $R^{2}$ & $0.76^{* *}$ & & & \\
\hline
\end{tabular}

Note. Control variable: baseline cigarettes smoked per day. ${ }^{*} p<0.05$. ${ }^{* *} p<0.01$.

There was no significant time effect on readiness to quit smoking $(\mathrm{p}>0.05)$, indicating no difference among scores over time.

The condition of sphericity was violated for the number of cigarettes smoked per day scores, the degrees of freedom were corrected using Huynh-Feldt estimates, and the adjusted results yielded a significant effect of time. Pairwise comparisons revealed significant decreases in the scores between baseline and the latter two time points ( $\mathrm{p}<0.05)$; however, there was no significant difference between the means at T2 and T3 (p $>0.05)$.
There was no significant time effect on the severity of nicotine addiction ( $p>0.05)$, indicating no differences among scores across time.

Behavior regulation predictors of smoking behavior change Change in number of cigarettes smoked per day was regressed onto the demographic characteristics and cognitive parameters of behavior regulation that were significantly correlated with the outcome variable. These predictors included number of close friends who smoke cigarettes $(\mathrm{r}=0.35, \mathrm{p}<0.05)$, relatedness need satisfaction $(\mathrm{r}=-0.44, \mathrm{p}<0.05)$, and smoking cessation self-efficacy $(r=-0.66, p<0.01)$.

The data were examined for violations of the test assumptions and none was noted. Test results indicated good model fit (Durbin Watson statistic = 1.9). The model with three predictors explained $17 \%$ of the variance in the number of cigarettes students smoked per day, controlling for the baseline smoking behavior $[\mathrm{F}(4,28)=22.66, \mathrm{p}<0.05]$. Examining the contribution of each of the independent variables to the model's predictive power, only smoking cessation self-efficacy was a significant independent predictor of the number of cigarettes smoked per day, when the overlapping effects of other variables in the model were controlled (Table 3 ). The partial correlation coefficient (-0.35) indicated that $12 \%$ of total variance in the outcome was uniquely explained by smoking cessation self-efficacy. For a unit increase in selfefficacy scores, the students experienced a 0.34 unit decrease in the number of cigarettes smoked per day, holding the effects of the number of friends who smoke and the relatedness need satisfaction constant. 
To summarize the study results, four of the cognitive parameters of college student smoking behavior regulation underwent significant changes. Students' level of autonomy need satisfaction, relatedness need satisfaction, autonomous motivation, and smoking cessation self-efficacy have been significantly increased. However, no significant differences were observed in competence need satisfaction or readiness to quit smoking. There was a significant reduction in students' rate of daily smoking (cigarettes per day) over time, although no change was captured in students' severity of nicotine addiction. Smoking cessation self-efficacy was the strongest behavior regulation predictor of smoking behavior in this sample of college students.

\section{DISCUSSION}

This exploratory trial of a novel smoking cessation intervention demonstrated that a theory-driven, text message-based motivational interviewing intervention could be a plausible approach to smoking behavior change in college smokers.

This method may offer a new way of treatment delivery for hard-to-reach populations. The change in the major outcome of cigarettes smoked per day is consistent with available evidence on the effects of technology-assisted smoking cessation interventions in young adults ${ }^{59}$.

Study findings highlight the behavior regulation process, as proposed by the Self-Determination Theory, and suggest that self-efficacy may play a role specific to smoking behavior. Smoking cessation self-efficacy was uniquely and negatively related to smoking behavior. This finding is consistent with recent research on factors influencing smoking behavior in college students ${ }^{60,61}$. Interventions capable of targeting this interaction hold great promise for smoking cessation in young adults. Research suggests that increased self-efficacy may influence smoking cessation preparedness, thereby increasing the readiness to quit and the rate of cessation, even in those who do not initially respond to treatment ${ }^{62}$. Recent findings also confirm that adult smokers who are not yet ready to quit are very receptive to mobile health interventions focusing on smoking reduction or cessation ${ }^{63}$.

Assessing college students' smoking cessation self-efficacy is key to identifying those at risk of having difficulty with the cessation progress. Identifying low smoking cessation selfefficacy allows the clinician to target ways to indirectly address unhealthy behaviors by increasing the individual's self-efficacy necessary to abstain from it. College students who identify the need to improve their smoking cessation self-efficacy may be more responsive to recruitment into cessation programs. However, in order to develop maximally effective interventions for this important, yet often overlooked target group, more research on the development of smoking cessation self-efficacy is needed, including a more thorough examination of the relationship between smoking behavior regulation and selfefficacy, and evidence-based individual-level skill building and coping strategies.

\section{Limitations}

The major limitations of this study are the self-selected nature of the sample and the self-report nature of the data. Convenience sampling may have led to bias due to underrepresentation or overrepresentation of certain subgroups of the study population, thus affecting generalizability of the research findings to a larger young adult population ${ }^{64}$. In addition, those who were included in the study may have differed in important ways (such as mental or physical health status) from those who were not.

The lack of a control group and a short follow-up assessment (potential overestimation of the changes while undergoing the intervention) warrant caution in interpretation of the results. Although participants were largely representative of the selected college population in racial diversity, they were primarily Caucasian, limiting the ability to generalize the findings to minority populations as well as those not enrolled in the large, metropolitan university. The self-report instruments that were used could also introduce the risk of a social desirability bias ${ }^{65}$. Future studies should include randomized and translational studies with a 6-month follow-up to capture the true long-term effect of the intervention and improve its effectiveness, and a biological marker to corroborate the selfreport data.

\section{CONCLUSIONS}

A pilot study is a necessary initial step in exploring an innovative intervention. Despite limitations of the study design, the findings provide preliminary evidence of the feasibility and potential utility of text message-based motivational interviewing intervention in smoking behavior change among college students. Although the present study was strengthened by employing a lower than recommended Type I error rate ${ }^{66}$, it was primarily intended to inform larger, more comprehensive investigations. Pending further investigation and replication of this intervention, MI could become an efficient and effective counseling approach for improving smoking cessation among college students. Today's colleges and universities serve a wide range of students from different socioeconomic, racial, national, ethnic backgrounds, making them prime locations for high impact interventions for long- 
term health behavior patterning. It is imperative that the research and clinical communities place greater emphasis on smoking cessation interventions for college students.

\section{REFERENCES}

1 World Health Organization. WHO report on the global tobacco epidemic, 2015: Raising taxes on tobacco. Available at: http:// www.who.int/tobacco/global_report/2015/report/en/ (accessed December 2016).

2. World Health Organization. WHO report on the global tobacco epidemic, 2013: Enforcing bans on tobacco advertising, promotion and sponsorship. Available at: http://www.who.int/tobacco/global_ report/2013/en/ (accessed December 2016).

3. Centers for Disease Control and Prevention. Current cigarette smoking among adults - United States, 2005 - 2015. MMWR Morb Mortal Wkly Rep. 2016;65(44):1205-1211.

doi: 10.15585/mmwr.mm6544a2

4. Centers for Disease Control and Prevention. Health effects of cigarette smoking. Smoking \& Tobacco Use. 2015. Available at: http://www.cdc.gov/tobacco/data_statistics/fact_sheets/health_ effects/effects_cig_smoking/(accessed December 2016)

5. Campaign for Tobacco-Free Kids. Toll of Tobacco in the United States. 2016. Available from: https://www.tobaccofreekids.org/ facts_issues/toll_us/ (accessed December 1, 2016).

6. United States Census Bureau. School Enrollment. 2015. Available from: http://www.census.gov/hhes/school/data/cps/2014/tables. html (accessed December 2016)

7. American College Health Association. American College Health Association-National College Health Assessment II: Undergraduate students. Reference group executive summary, Fall 2015. Available at: http://www.acha-ncha.org/reports_ACHA-NCHAIIc.html (accessed December 1, 2016)

8. Rigotti N, Lee JE, Wechsler H. US college students' use of tobacco products: Results of a national survey. JAMA. 2000;284(6):699705. doi: $10.1001 /$ jama.284.6.699

9. Jha P, Ramasundarahettige C, Landsman V, et al. 21st-century hazards of smoking and benefits of cessation in the United States. N Engl J Med. 2013;368(4):341-350. doi: 10.1056/NEJMsa1211128

10. Rollnick S, Miller WR, Butler CC. Motivational Interviewing in health care: Helping patients change behavior. New York, NY: The Guilford Press; 2008.

11. Griffin KW, Botvin GJ. Evidence-based interventions for preventing substance use disorders in adolescents. Child Adolesc Psychiatr Clin N Am. 2010;19(3):505-526. doi: $10.1016 /$ j.chc.2010.03.005

12. College Tobacco Prevention Resource. College Tobacco Facts. 2016. Available at: http://www.ttac.org/services/college/facts/ cessation.html (accessed December 2016).

13. Suls JM, Luger TM, Curry SJ, Mermelstein RJ, Sporer AK, An LC. Efficacy of smoking-cessation interventions for young adults: A meta-analysis. Am J Prev Med. 2012;42(6):655-662. doi: 10.1016/j.amepre.2012.02.013

14. Orr JA, King RJ. Mobile phone SMS messages can enhance healthy behaviour: a meta-analysis of randomised controlled trials. Health psychology review. 2015;9(4):397-416. doi: 10.1080/17437199.2015.1022847

15. Butler KM, Fallin A, Ridner SL. Evidence-based smoking cessation for college students. Nurs Clin North Am. 2012;47(1):21-30. doi: 10.1016/j.cnur.2011.10.007

16. Miller WR, Rollnick S. Motivational Interviewing: Preparing people for change 2ed. New York: The Guilford Press; 2002.

17. Bock BC, Heron KE, Jennings EG, Magee JC, Morrow KM. User preferences for a text message-based smoking cessation intervention. Health Educ Behav. 2013;40(2):152-159. doi: 10.1177/1090198112463020

18. Devries KM, Kenward MG, Free CJ. Preventing smoking relapse using text messages: Analysis of data from the txt2stop trial. Nicotine \& tobacco research. 2013;15(1):77-82. doi: $10.1093 / \mathrm{ntr} / \mathrm{nts} 086$

19. Free C, Knight R, Robertson S, et al. Smoking cessation support delivered via mobile phone text messaging (txt2stop): A singleblind, randomised trial. Lancet. 2011;378(9785):49-55.

doi: 10.1016/S0140-6736(11)60701-0

20. Gritz ER, Danysh HE, Fletcher FE, et al. Long-term outcomes of a cell phone-delivered intervention for smokers living with HIV/ AIDS. Clin Infect Dis. 2013;57(4):608-615.

doi: $10.1093 / \mathrm{cid} / \mathrm{cit} 349$

21. Scott-Sheldon LAJ, Lantini R, Jennings EG, et al. Text MessagingBased Interventions for Smoking Cessation: A Systematic Review and Meta-Analysis. Bars M, ed. JMIR mHealth and uHealth. 2016;4(2):e49. doi:10.2196/mhealth.5436.

22. Militello LK, Kelly SA, Melnyk BM. Systematic review of textmessaging interventions to promote healthy behaviors in pediatric and adolescent populations: Implications for clinical practice and research. Worldviews on evidence-based nursing. 2012;9(2):66-77. doi: 10.1111/j.1741-6787.2011.00239.x

23. Whittaker R, McRobbie H, Bullen C, Borland R, Rodgers A, Gu Y. Mobile phone-based interventions for smoking cessation. Cochrane database of systematic reviews. 2012;11:CD006611. doi: 10.1002/14651858.CD006611.pub4

24. Ybarra ML, Holtrop JS, Prescott TL, Rahbar MH, Strong D. Pilot RCT results of Stop My Smoking USA: A text messaging-based smoking cessation program for young adults. Nicotine \& tobacco research. 2013;15(8):1388-1399.

doi: $10.1093 / \mathrm{ntr} / \mathrm{nts} 339$

25. Miranda JAR, Ruiz CAJ, Rebollo JCS. Smoking Cessation. Clinical Pulmonary Medicine. 2013;20(3):129-136. doi: 10.1097/CPM.0b013e31828fda4c

26. Heckman CJ, Egleston BL, Hofmann MT. Efficacy of motivational interviewing for smoking cessation: a systematic review and metaanalysis. Tob control. 2010;19(5):410-416. doi: 10.1136/tc.2009.033175

27. Mason MJ, Campbell L, Way T, Keyser-Marcus L, Benotsch E, Mennis J, ... \& Stembridge DR. Development and outcomes of a text messaging tobacco cessation intervention with urban adolescents. Substance Abuse.2015; 36(4), 500-506. doi:10.1080/08897077.2014.987946

28. Ryan RM, Deci EL. Self-determination theory and the facilitation of intrinsic motivation, social development, and well-being. Am Psychol. 2000;55(1):68-78. doi: 10.1037/0003-066X.55.1.68

29. Ryan RM, Patrick H, Deci EL, Williams GC. Facilitating health behaviour change and its maintenance: Interventions based on Self-Determination Theory. European Health Psychologist. 2008;10(1):2-5.

30. Deci E, Ryan R. The «What» and «Why» of goal pursuits: Human needs and the self-determination of behavior. Psychological Inquiry. 2000;11(4):227-268. 


\section{Research paper}

doi:10.1207/ S15327965PLI1104_01

31. Miller WR, Rollnick S. Motivational Interviewing: Helping people change. 3 ed. New York: The Guilford Press; 2013.

32. Lundahl B, Burke BL. The effectiveness and applicability of motivational interviewing: A practice-friendly review of four metaanalyses. J Clin Psychol. 2009;65(11):1232-1245. doi: $10.1002 /$ jclp.20638

33. Vodopivec-Jamsek V, de Jongh T, Gurol-Urganci I, Atun R, Car J. Mobile phone messaging for preventive health care. Cochrane Database of Systematic Reviews. 2012;12:CD007457. doi: 10.1002/14651858.CD007457.pub2

34. Faul F, Erdfelder E, Lang AG, Buchner A. G*Power 3: A flexible statistical power analysis program for the social, behavioral, and biomedical sciences. Behavior research methods. 2007;39(2):175191.

doi: 10.3758/BF03193146

35. Villanti AC, McKay HS, Abrams DB, Holtgrave DR, Bowie JV. Smoking-cessation interventions for U.S. young adults: A systematic review. Am J Prev Med. 2010;39(6):564-574.

doi: 10.1016/j.amepre.2010.08.009

36. Gagné M. The Role of autonomy support and autonomy orientation in prosocial behavior Engagement. Motivation and Emotion. 2003;27(3):199-223.

doi: 10.1023/A:1025007614869

37. Johnston MM, Finney SJ. Measuring basic needs satisfaction: Evaluating previous research and conducting new psychometric evaluations of the Basic Needs Satisfaction in General Scale. Contemporary Educational Psychology. 2010;35(4):280-296. doi: 10.1016/j.cedpsych.2010.04.003

38. Molix LA, Nichols CP. Satisfaction of basic psychological needs as a mediator of the relationship between community esteem and wellbeing. International Journal of Wellbeing. 2013;3(1):20-34. doi:10.5502/ijw.v3i1.2

39. Williams GC, Gagné M, Ryan RM, Deci EL. Facilitating autonomous motivation for smoking cessation. Health Psychol. 2002;21(1):4050 . doi: 10.1037//0278-6133.21.1.40

40. Levesque CS, Williams GC, Elliot D, Pickering MA, Bodenhamer B, Finley PJ. Validating the theoretical structure of the Treatment Self-Regulation Questionnaire (TSRQ) across three different health behaviors. Health education research. 2007;22(5):691-702. doi: 10.1093/her/cyl148

41. Williams GC, Niemiec CP, Patrick H, Ryan RM, Deci EL. The importance of supporting autonomy and perceived competence in facilitating long-term tobacco abstinence. Ann Behav Med. 2009;37(3):315-324.

doi: 10.1007/s12160-009-9090-y

42. Williams GC, McGregor H, Sharp D, et al. A self-determination multiple risk intervention trial to improve smokers' health. J Gen Intern Med. 2006;21(12):1288-1294. doi: $10.1111 / j .1525-1497.2006 .00621 . x$

43. Etter JF, Bergman MM, Humair JP, Perneger TV. Development and validation of a scale measuring self-efficacy of current and former smokers. Addiction. 2000;95(6):901-913. doi: 10.1046/j.1360-0443.2000.9569017.x

44. Biener L, Abrams DB. The Contemplation Ladder: Validation of a measure of readiness to consider smoking cessation. Health Psychol. 1991;10(5):360-365.

doi: $10.1037 / 0278-6133.10 .5 .360$
45. Amodei N, Lamb RJ. Convergent and concurrent validity of the Contemplation Ladder and URICA scales. Drug Alcohol Depend. 2004;73(3):301-306.

doi: 10.1016/j.drugalcdep.2003.11.005

46. Abrams DB, Herzog TA, Emmons KM, Linnan L. Stages of change versus addiction: A replication and extension. Nicotine \& tobacco research. 2000;2(3):223-229.

doi: 10.1080/14622200050147484

47. Herzog TA, Blagg CO. Are most precontemplators contemplating smoking cessation? Assessing the validity of the stages of change. Health Psychol. 2007;26(2):222-231.

doi: 10.1037/0278-6133.26.2.222

48. Martin RA, Rohsenow DJ, MacKinnon SV, Abrams DB, Monti PM. Correlates of motivation to quit smoking among alcohol dependent patients in residential treatment. Drug Alcohol Depend. 2006;83(1):73-78.

doi: 10.1016/j.drugalcdep.2005.10.013

49. Etter JF, Le Houezec J, Perneger TV. A self-administered questionnaire to measure dependence on cigarettes: The Cigarette Dependence Scale. Neuropsychopharmacology. 2003;28(2):359370 .

doi: 10.1038/sj.npp.1300030

50. Etter JF. Comparing the validity of the Cigarette Dependence Scale and the Fagerstrom Test for Nicotine Dependence. Drug Alcohol Depend. 2008;95(1-2):152-159.

doi: 10.1016/j.drugalcdep.2008.01.017

51. Etter JF, Le Houezec J, Huguelet P, Etter M. Testing the Cigarette Dependence Scale in 4 samples of daily smokers: Psychiatric clinics, smoking cessation clinics, a smoking cessation website and in the general population. Addict Behav. 2009;34(5):446-450. doi: 10.1016/j.addbeh.2008.12.002

52. Stavem K, Rogeberg OJ, Olsen JA, Boe J. Properties of the Cigarette Dependence Scale and the Fagerstrom Test of Nicotine Dependence in a representative sample of smokers in Norway. Addiction. 2008;103(9):1441-1449. doi: 10.1111/j.1360-0443.2008.02278.x

53. Villanti AC, McKay HS, Abrams DB, Holtgrave DR, Bowie JV. Smoking-cessation interventions for U.S. young adults: A systematic review. Am J Prev Med. 2010; 39(6), 564-574. doi: 10.1016/j.amepre.2010.08.009

54. Orr JA, King, RJ. Mobile phone SMS messages can enhance healthy behaviour: a meta-analysis of randomised controlled trials. Health Psychology Review. 2015; 9(4), 397-416.

doi: 10.1080/17437199.2015.1022847

55. Kentucky Cabinet for Health and Family Services. Quit Now Kentucky. 2013. Available at: http://chfs.ky.gov/dph/mch/hp/ quitline.htm. (accessed December 2016)

56. JPMorgan Chase \& Co. Chase Person-to-Person Quick Pay. 2013. Available at: https://www.chase.com/online/services/quickpay. htm (accessed December 2016)

57. Harris PA, Taylor R, Thielke R, Payne J, Gonzalez N, Conde JG. Research electronic data capture (REDCap) - a metadata-driven methodology and workflow process for providing translational research informatics support. Journal of biomedical informatics. 2009;42(2):377-381.

doi: $10.1016 /$ j.jbi.2008.08.010

58. IBM ${ }^{\circledR}$. SPSS $®$ software 2013. Available at: http://www-01.ibm. com/software/analytics/spss/. (accessed December 2016)

59. Brown J. A review of the evidence on technology-based interventions for the treatment of tobacco dependence in college 


\section{Research paper}

health. Worldviews on evidence-based nursing. 2013;10(3):150-

162.

doi: $10.1111 /$ wvn. 12000

60. Mee S. Self-efficacy: A mediator of smoking behavior and depression among college students. Pediatric Nursing. 2014;40(1):9-15, 37.

61. Kim N-J, Hong H-S. Influence of stress, self-efficacy for smoking cessation, smoking temptation and nicotine dependency in male college students who smoke. Journal of Korean Biological Nursing Science. 2016;18(1):1-8.

doi: 10.7586/jkbns.2016.18.1.1

62. Burns RJ, Rothman AJ, Fu SS, Lindgren B, Vock DM, Joseph AM. Longitudinal care improves cessation in smokers who do not initially respond to treatment by increasing cessation self-efficacy, satisfaction, and readiness to quit: A mediated moderation analysis. Ann Behav Med. 2016;50(1):58-69.

doi: 10.1007/s12160-015-9732-1

63. McClure JB, Heffner J, Hohl S, Klasnja P, Catz SL. Design Considerations for mHealth Programs Targeting Smokers Not Yet Ready to Quit: Results of a Sequential Mixed-Methods Study. JMIR mHealth and uHealth. 2017;5(3):e31. doi: 10.2196/mhealth.6845

64. Polit DF, Beck TB. Nursing Research: Generating and assessing evidence for nursing practice. Philadelphia: Wolters Kluwer/ Lippincott Williams \& Wilkins; 2012.

65. Shadish WR, Cook TD, Campbell DT. Experimental and quasiexperimental designs for generalized causal inference. Boston, MA: Houghton Mifflin; 2002.

66. Moore CG, Carter RE, Nietert PJ, Stewart PW. Recommendations for planning pilot studies in clinical and translational research. Clin Transl Sci.2011; 4(5): 332-337.

doi: 10.1111/j.1752-8062.2011.00347.x

ACKNOWLEDGEMENTS

The authors would like to thank Dr. Richard Cloud for the motivational interviewing training and support and Dr. Timothy Crawford for the guidance with statistical data analyses.

CONFLICT OF INTERESTS The authors have completed and submitted the ICMJE Form for Disclosure of Potential Conflicts of Interest and none was reported.

\section{FUNDING}

This study was supported by research grant from the Sigma Theta Tau International, Iota Zeta Chapter.

PROVENANCE AND PEER REVIEW Not commissioned; externally peer reviewed 